\title{
Urothelial Dysplasia
}

National Cancer Institute

\section{Source}

National Cancer Institute. Urothelial Dysplasia. NCI Thesaurus. Code C39856.

A morphologic finding indicating the presence of dysplastic changes in the transitional cell epithelium of the urinary tract. 